03

\title{
Влияние электронного и дырочного допирования на транспортные характеристики халькогенидных систем
}

\author{
(C) О.Б. Романова ${ }^{1}$, С.С. Аплеснин ${ }^{1,2}$, Л.В. Удод ${ }^{1,2}$ \\ ${ }^{1}$ Институт фризики им. Л.В. Киренского ФИЦ КНЦ СО РАН, \\ Красноярск, Россия \\ ${ }^{2}$ Сибирский государственный университет науки и технологий им. М.Ф. Решетнева, \\ Красноярск, Россия \\ E-mail: rob@iph.krasn.ru
}

Поступила в Редакцию 24 декабря 2020 г.

В окончательной редакции 24 декабря 2020 г.

Принята к публикации 19 января 2021 г.

Проведены исследования электрических свойств и эффекта Холла в полупроводниковых соединениях $\mathrm{Ag}_{0.01} \mathrm{Mn}_{0.99} \mathrm{~S}$ и $\mathrm{Tm}_{0.01} \mathrm{Mn}_{0.99} \mathrm{~S}$ в интервале температур $80-400 \mathrm{~K}$ в магнитном поле $12 \mathrm{kOе.} \mathrm{Установлен}$ механизм проводимости, зависящий от типа допирования и концентрации из вольт-амперных характеристик. При замещении марганца серебром найден моттовский тип, а замещение тулием вызывает омическую проводимость. Из константы Холла найдена подвижность и тип носителей заряда.

Ключевые слова: полупроводники, проводимость, константа Холла, подвижность.

DOI: 10.21883/FTT.2021.05.50808.269

\section{1. Введение}

Исследование электронных явлений и механизма проводимости в неупорядоченных системах занимают одно из центральных мест в физике конденсированного состояния. Оно обусловлено, как правило, практической важностью использования таких систем, так и внутренней логикой развития физики. В настоящее время интенсивно исследуются халькогениды европия [1,2], селениды $\mathrm{CdCr}_{2} \mathrm{Se}_{4}, \mathrm{HgCr}_{2} \mathrm{Se}_{4}$ [3-5], топологические изоляторы $\mathrm{Bi}_{2} X_{3}(X=\mathrm{Se}, \mathrm{Te})[6]$ и сульфиды марганца $M e_{X} \mathrm{Mn}_{1-X}(M e-3 \mathrm{~d}-$ и 4f-элементы), синтезированные на основе моносульфида марганца [7-9], в которых влияние магнитного порядка и допирования на транспортные свойства проявляется в виде магниторезистивного и гальваномагнитного эффектов, а также перехода металл-диэлектрик.

Нестехиометрия в магнитном полупроводнике $\alpha-\mathrm{MnS}$ приводит к существенному изменению транспортных и электрических свойств. Моносульфид марганца является антиферромагнетиком со вторым типом упорядочения на гранецентрированной кубической решетке (ГЦК) с температурой Нееля $T_{N}=150 \mathrm{~K}$ и имеет полупроводниковый характер проводимости [10]. Согласно холловским измерениям носителями тока в области температур $T<450 \mathrm{~K}$ являются дырки ( $p$-типа) локализованные на 3d-уровнях иона марганца и характеризуется низкими значениями подвижности носителей тока $[11,12]$. Интерес к моносульфиду марганца возрос, благодаря обнаружению в нем эффекта магнитосопротивления, который порядка величины $-12 \%$ наблюдался в плоскости (111)
$\alpha-\mathrm{MnS}$, в то время как для плоскости (100) преобладающим являлось положительное значение магнитосопротивления при температурах выше $T_{N}$ в магнитном поле $10 \mathrm{kOe}$ [13]. Величина магниторезистивного эффекта значительно увеличилась, при допировании этой системы 3d-металлами и редкоземельными элементами $[14,15]$.

В электрически неоднородных полупроводниках проводимость определяется рассеянием носителей тока в матрице на заряженных примесях, так и перескоковым механизмом по примесным состояниям. При достаточно больших концентрациях, когда толщина потенциального барьера между областями с повышенной подвижностью, сравнима со средним пробегом носителей тока, проводимость будет реализоваться по двум каналами и имеет нелинейный характер [16]. В системе $M e_{X} \mathrm{Mn}_{1-X} \mathrm{~S}$ с концентрацией $X=0.01$ замещение марганца трехвалентным ионом тулия приведет к электронному допированию $t_{2 g}$-оболочки, а замещение одновалентным ионом серебра к дырочному допированию с образованием трехвалентных ионов марганца и к вырождению $t_{2 g}$ и $e_{g}$ орбиталей, что индуцирует локальные ян-теллеровские эффекты. При малых концентрациях появится дополнительный вклад в рассеяние носителей тока на локальных деформациях решетки, и как следствие изменение типа проводимости и характера подвижности.

В связи с этим, целью настоящей работы являлось установить влияние корреляции примесных состояний на механизм проводимости, подвижность и тип носителей тока при электронном и дырочном допировании в системе моносульфида марганца. 


\section{2. Методика измерений}

Твердые растворы $\mathrm{Ag}_{0.01} \mathrm{Mn}_{0.99} \mathrm{~S}$ и $\mathrm{Tm}_{0.01} \mathrm{Mn}_{0.99} \mathrm{~S}$ были синтезированы кристаллизацией из расплава полученных порошковых сульфидов в стеклоуглеродных тиглях и кварцевом реакторе [16,17]. Рентгеноструктурный анализ (РСА) был выполнен на рентгеновской установке ДРОН-3 с использованием $\mathrm{Cu} K_{\alpha}$-излучения при $T=300 \mathrm{~K}$.

Влияние электронного и дырочного допирования на транспортные характеристики определялось из вольтамперных характеристик (BAX), измеренных при фиксированных температурах четырехконтактным методом, на образцах в виде параллелепипедов с индиевыми омическими контактами. Измерение холловского напряжения проводилось на постоянном токе в интервале температур $100-400 \mathrm{~K}$ в магнитном поле $12 \mathrm{kOе}$. При измерении были учтены вклады паразитных эдс, возникающих вследствие побочных гальваномагнитных и термомагнитных эффектов, а также неэквипотенциальность в расположении холловских зондов путем измерения в нулевом магнитном поле.

\section{3. Результаты измерений и обсуждение}

Согласно результатам рентгеноструктурного анализа образцы $\mathrm{Ag}_{0.01} \mathrm{Mn}_{0.99} \mathrm{~S}$ и $\mathrm{Tm}_{0.01} \mathrm{Mn}_{0.99} \mathrm{~S}$ являются однофазными поликристаллическими соединениями, которые имеют гранецентрированную кубическую структуру типа $\mathrm{NaCl}$, характерную для моносульфида марганца [18]. C увеличением степени катионного замещения $(X)$ параметр элементарной ячейки а незначительно увеличивается в соответствии с возрастанием ионного радиуса замещающего элемента $(r=0.083 \mathrm{~nm}$ для $\mathrm{Mn}$, $r=0.113 \mathrm{~nm}$ для $\mathrm{Ag}$ и $r=0.117 \mathrm{~nm}$ для Tm). Результаты

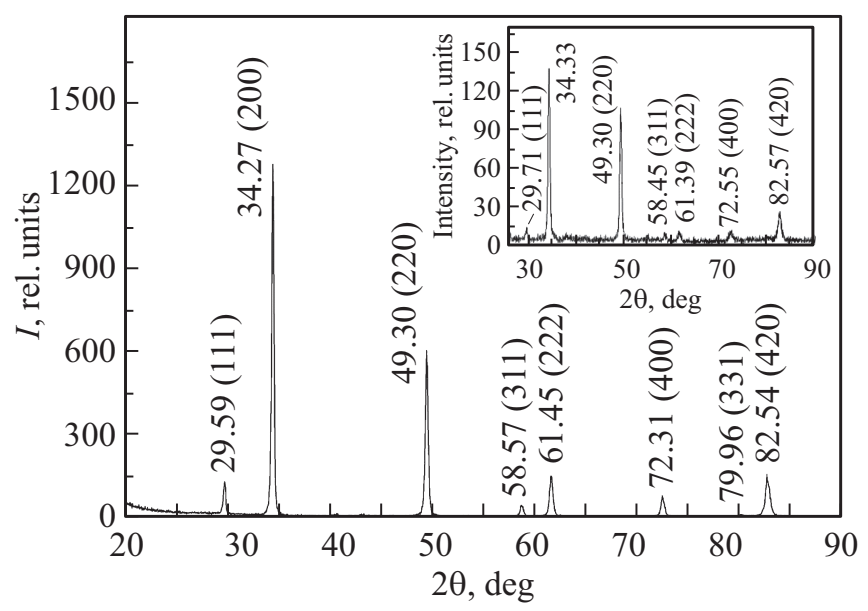

Рис. 1. Результаты рентгеноструктурного анализа твердых растворов $\mathrm{Ag}_{0.01} \mathrm{Mn}_{0.99} \mathrm{~S}$ при $300 \mathrm{~K}$. На вставке: рентгенограмма для образца $\mathrm{Tm}_{0.01} \mathrm{Mn}_{0.99} \mathrm{~S}$.

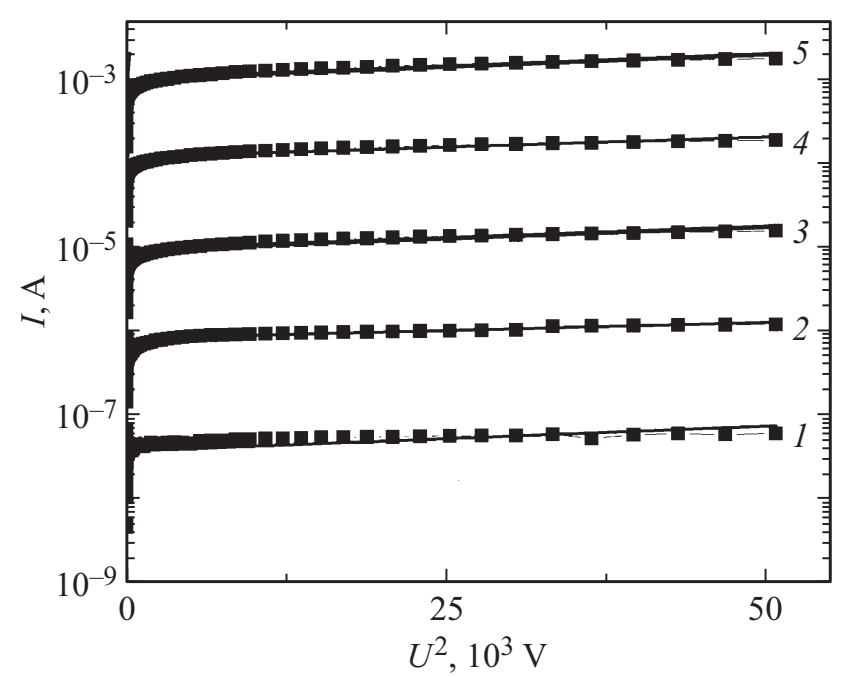

Рис. 2. Вольт-амперная характеристика измеренная при $T=100$ (1), 140 (2), 200 (3), 280 (4), 360 K (5) для образца $\mathrm{Ag}_{0.01} \mathrm{Mn}_{0.99} \mathrm{~S}$.

рентгеноструктурного анализа для этих систем представлены на рис. 1.

Анализ вольт-амперных характеристик (BAX) исследуемых образцов $\mathrm{Ag}_{0.01} \mathrm{Mn}_{0.99} \mathrm{~S}$ и $\mathrm{Tm}_{0.01} \mathrm{Mn}_{0.99} \mathrm{~S}$ проведен на основе механизма Пула-Френкеля, Мотта и закона Ома. На рис. 2 представлены зависимости тока $(I)$ от квадрата напряжения $(U)$ для температур (100, 140, $200,280$ и $360 \mathrm{~K})$. Анализ угла наклона кривых $I\left(U^{2}\right)$ представленных на рис. 2 позволил установить наличие линейных областей во всем интервале напряжений при температурах выше $100 \mathrm{~K}$. Линейность этих зависимостей указывает на преобладающий вклад токов, ограниченных пространственным зарядом [19], который описывается квадратичным законом Мотта. Экспериментальные данные $\mathrm{BAX}$ для системы $\mathrm{Ag}_{0.01} \mathrm{Mn}_{0.99}$ удовлетворительно описываются уравнением (1), а проводимость законом Мотта [20]:

$$
j=9 / 8 \tau_{\mu} \sigma_{0} \mu U^{2} / L^{3},
$$

где $j$ - плотность тока, $\tau_{\mu}$ - максвелловское время релаксации, $\sigma_{0}$ - электропроводность в объеме материала в отсутствии инжекции носителей тока, $\mu-$ подвижность носителей тока, $U$ - приложенное напряжение, $L$ - толщина образца. Механизм проводимости в $\mathrm{Ag}_{X} \mathrm{Mn}_{1-X} \mathrm{~S}$ зависит от концентрации замещения. Так для $x=0.05$ выполняется закон Ома, ВАХ имеет линейный вид [17].

Электронное допирование качественно меняет механизм проводимости. На рис. 3 представлена ВАХ твердого раствора $\mathrm{Tm}_{0.01} \mathrm{Mn}_{0.99} \mathrm{~S}$ в логарифмическом масштабе в области температур 120-280 K. В этом интервале температур зависимость силы тока от напряжения имеет линейный характер. Из наклона кривых, который не превышал единицу, установлен омический 


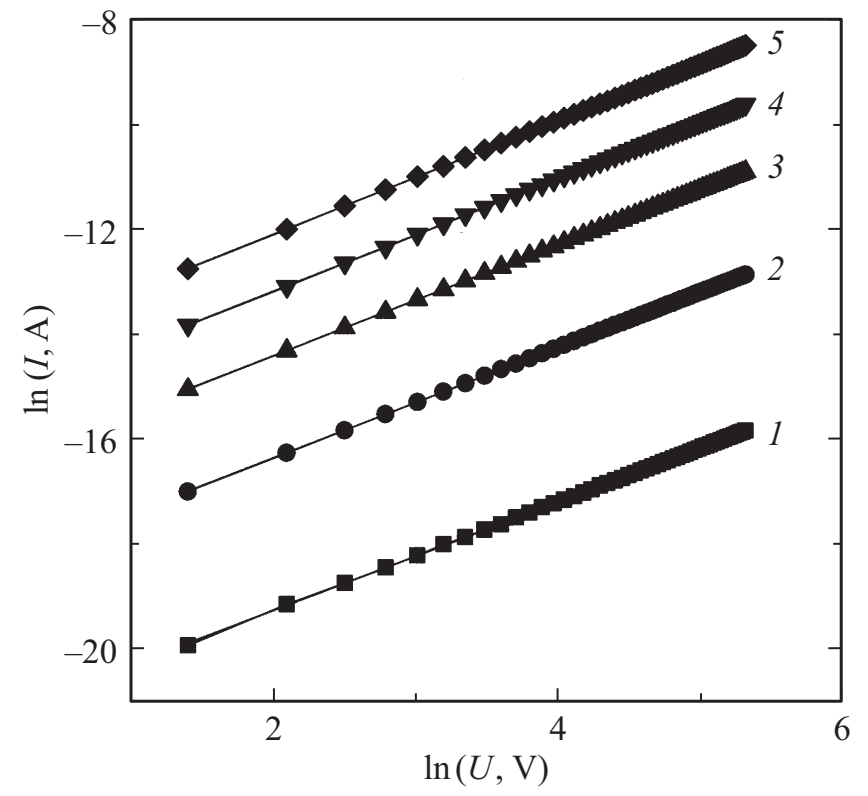

Рис. 3. Вольт-амперная характеристика в логарифмическом масштабе для поликристалла $\mathrm{Tm}_{0.01} \mathrm{Mn}_{0.99} \mathrm{~S}$ при $T=120$ (1), 160 (2), 200 (3), 240 (4), $280 \mathrm{~K}(5)$.

механизм проводимости для этой системы. Для больших концентраций $x>0.05$ в системе $\mathrm{Tm}_{X} \mathrm{Mn}_{1-X} \mathrm{~S}$ BAX является нелинейной [16]. Вид вольт-амперных характеристик, полученных при различных температурах, существенно не меняется. Увеличение проводимости вызвано ростом концентрации и подвижности носителей тока.

Тип носителей тока и их подвижность в результате электронного ( $\mathrm{Tm}$ ) и дырочного ( $\mathrm{Ag}$ ) допирования найдем из исследования гальваномагнитных свойств. При $T<450 \mathrm{~K}$ в моносульфиде марганца основными носителями тока являются дырки с подвижностью $0.065 \mathrm{~cm}^{2} \cdot \mathrm{V}^{-1} \cdot \mathrm{s}^{-1}$ при $T=435 \mathrm{~K}[11]$. Выше $450 \mathrm{~K}$ носителями становятся электроны. На рис. $4, a, b$ представлены температурные зависимости константы Холла $\left(R_{H}\right)$ для $\mathrm{Ag}_{0.01} \mathrm{Mn}_{0.99} \mathrm{~S}$ и $\mathrm{Tm}_{0.01} \mathrm{Mn}_{0.99} \mathrm{~S}$ соответственно. Вид кривых $R_{H}(T)$ зависит от типа замещающего элемента. В исследуемых нами системах, как и в исходном моносульфиде марганца, наблюдается смена знака основных носителей тока по температуре. В области низких температур при $T<95 \mathrm{~K}$ для системы $\mathrm{Ag}_{0.01} \mathrm{Mn}_{0.99} \mathrm{~S}$ и при $T<100 \mathrm{~K}$ для $\mathrm{Tm}_{0.01} \mathrm{Mn}_{0.99} \mathrm{~S}$ преобладает дырочный тип носителей тока. В этой области температур, согласно литературным данным [21] наблюдается сжатие решетки исходной матрицы моносульфида марганца, которое сопровождается ромбоэдрическим искажением, что подтверждается данными коэффициента теплового расширения решетки.

В системе $\mathrm{Ag}_{0.01} \mathrm{Mn}_{0.99} \mathrm{~S}$ при замещении марганца серебром $R_{H}$ меняет знак в интервале температур $95-125 \mathrm{~K}$ и выше $350 \mathrm{~K}$, имеет широкий максимум в области $240-300 \mathrm{~K}$ (рис. 4,a). На рис. 5, $a$ показано, что выше $200 \mathrm{~K}$ подвижность основных носителей тока дырочного типа резко возрастает и проходит через максимум при $250 \mathrm{~K}$.

Уменьшение константы Холла на два порядка по сравнению с $\mathrm{Ag}_{0.01} \mathrm{Mn}_{0.99} \mathrm{~S}$ обнаружено в результате электронного допирования в $\mathrm{Tm}_{0.01} \mathrm{Mn}_{0.99} \mathrm{~S}$ и представлено на рис. $4, b$. В области магнитного фазового перехода $\left(T_{N}=172 \mathrm{~K}\right)$ для $\mathrm{Tm}_{0.01} \mathrm{Mn}_{0.99} \mathrm{~S}$, постоянная Холла принимает отрицательные значения и наблюдается небольшое увеличение подвижности носителей тока (рис. 5, $b$ ). При нагревании выше $200 \mathrm{~K}$ подвижность растет и достигает максимального значения выше комнатной температуры. Еще одна смена знака $R_{H}$ с отрицательного на положительный наблюдается в окрестности $360 \mathrm{~K}$.

Из исследований гальваномагнитных свойств твердых растворов $\mathrm{Tm}_{0.01} \mathrm{Mn}_{0.99} \mathrm{~S}$ и $\mathrm{Ag}_{0.01} \mathrm{Mn}_{0.99} \mathrm{~S}$ следует, что замещение катионов $\mathrm{Mn}^{+2}$ ионами $\mathrm{Ag}^{+1}$ и $\mathrm{Tm}^{+3}$ приводит к появлению в этих веществах двух типов носителей тока: дырок и электронов. Эти соединения можно отнести к полупроводникам со смешанным типом проводимости.

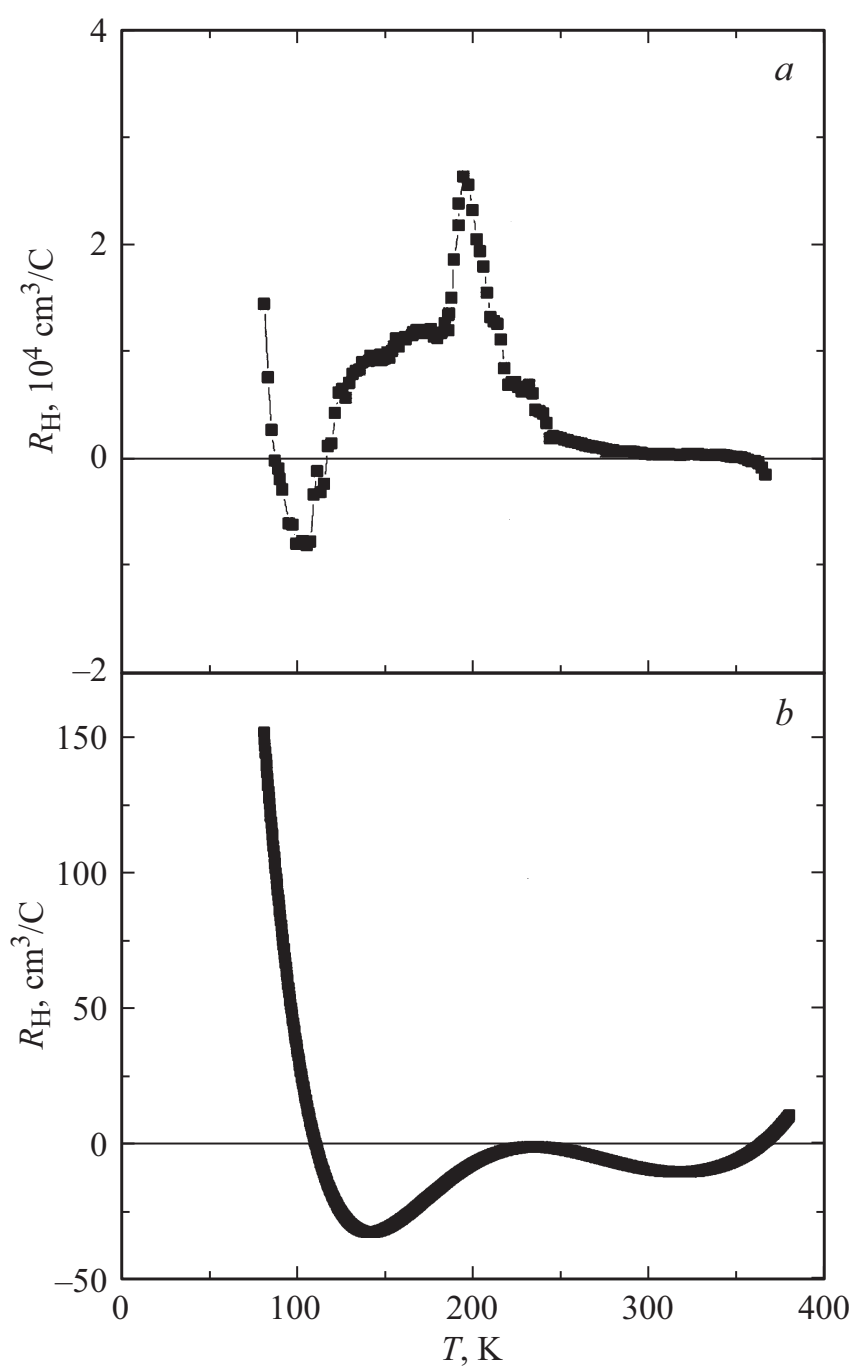

Рис. 4. Температурные зависимости коэффициента Холла для $\mathrm{Ag}_{0.01} \mathrm{Mn}_{0.99} \mathrm{~S}(a)$ и $\mathrm{Tm}_{0.01} \mathrm{Mn}_{0.99} \mathrm{~S}(b)$. 


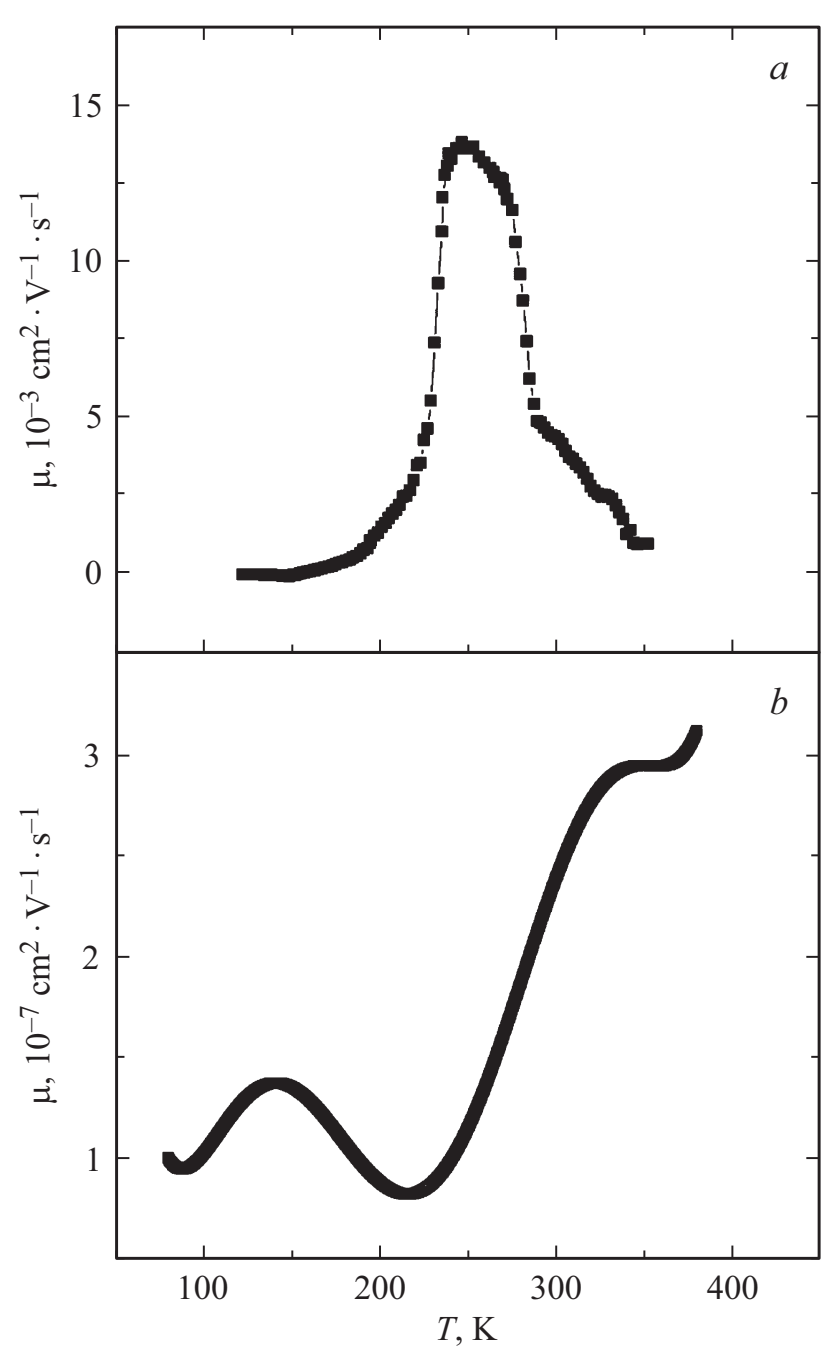

Рис. 5. Температурные зависимости подвижности образцов $\mathrm{Ag}_{0.01} \mathrm{Mn}_{0.99} \mathrm{~S}(a)$ и $\mathrm{Tm}_{0.01} \mathrm{Mn}_{0.99} \mathrm{~S}(b)$.

Соотношение между концентрацией дырок и электронов определяет тип носителей тока, который изменяется с температурой и зависит от типа замещающего элемента.

\section{4. Заключение}

Установлено, что механизм проводимости халькогенидных систем $M e_{X} \mathrm{Mn}_{1-X} \mathrm{~S}$ зависит от концентрации и типа замещающего элемента. Так проводимость $\mathrm{Ag}_{0.01} \mathrm{Mn}_{0.99} \mathrm{~S}$ описывается законом Мотта, а для $\mathrm{Tm}_{0.01} \mathrm{Mn}_{0.99} \mathrm{~S}$ законом Ома в широком температурном интервале. Из холловских измерений определены температурные области, где наблюдается изменение типа носителей тока и аномальное поведение их подвижности.

\section{Финансирование работы}

Исследование выполнено при финансовой поддержке РФФИ и БРФФИ в рамках научного проекта № 20-52-00005.

\section{Конфликт интересов}

Авторы заявляют, что у них нет конфликта интересов.

\section{Список литературы}

[1] W. Boncher, H. Dalafu, N. Rosa. Coord. Chem. Rev. 289-290, 279 (2015).

[2] M. Schlipf, M. Betzinger, M. Leẑaic, C. Friedrich, S. Blugel. Phys. Rev. B 88, 094433 (2013).

[3] Н.И. Солин, Н.М. Чеботаев. ФТТ 39, 5, 848 (1997).

[4] Г.И. Виноградова, Л.В. Анзина, В.Г. Веселаго, М.В. Глушков, Т.Н. Менщикова, Э.Г. Жуков. ФТТ 49, 5, 865 (2007).

[5] М.М. Казанин, В.В. Каминский, М.А. Гревцев. ФТТ 53, 7 , 887 (2019).

[6] Haijun Zhang, Chao-Xing Liu, Xiao-Liang Qi, Xi Dai, Zhong Fang, Shou-Cheng Zhang. Nature Phys. 5, 438 (2009).

[7] O.B. Romanova, L.I. Ryabinkina, V.V. Sokolov, A.Yu. Pichugin, D.A. Velikanov, D.A. Balaev, A.I. Galyas, O.F. Demidenko, G.I. Makovetskii, K.I. Yanushkevich. Solid State Commun. 150, 602 (2010).

[8] С.С. Аплеснин, О.Б. Романова, А.М. Харьков, А.И. Галяс. ФTT 57, 5, 872 (2015).

[9] S.S. Aplesnin, O.N. Bandurina, O.B. Romanova, L.I. Ryabinkina, A.D. Balaev, E.V. Eremin. J. Phys. Condens. Matter 22, 226006 (2010).

[10] С.С. Аплеснин, О.Б. Романова, О.Ф. Демиденко, К.И. Янушкевич. Магнитные фазовые переходы и кинетические свойства халькогенидов $3 d$-металлов. Сибирский гос. аэрокосм. ун-т, Красноярск (2017). 208 с.

[11] H.H. Heikens, C.F. van Bruggen, C.J. Haas. Phys. Chem. Solids 39, 833 (1978).

[12] H.H. Heikens, G.A. Wiegers, C.F. van Bruggen. Solid State Commun. 24, 205 (1977).

[13] S.S. Aplesnin, L.I. Ryabinkina, G.M. Abramova, O.B. Romanova, A.M. Vorotynov, D.A. Velikanov, N.I. Kiselev, A.D. Balaev. Phys. Rev. B 71, 12, 125204 (2005)

[14] S.S. Aplesnin, M.N. Sitnikov, O.B. Romanova, A.Yu. Pichugin. Phys. Status Solidi B 253, 9, 1771 (2016).

[15] S.S. Aplesnin, L.I. Ryabinkina, O.B. Romanova, A.M. Har'kov, M.V. Gorev, A.D. Balaev, E.V. Eremin, A.F. Bovina. Solid State Commun. 150, 564 (2010).

[16] S.S. Aplesnin, M.N. Sitnikov, A.M. Kharkov, A.N. Masyugin, V.V. Kretinin, O.B. Fisenko, M.V. Gorev. Phys. Status Solidi B 256, 1900043 (2019).

[17] O.B. Romanova, S.S. Aplesnin, L.V. Udod, M.N. Sitnikov, V.V. Kretinin, K.I. Yanushkivich, D.A. Velikanov. J. Appl. Phys. 125, 17, 175706 (2019).

[18] Д. Воган, Дж. Крейг. Химия сульфидных материалов. Мир, М. (1981). $575 \mathrm{c}$.

[19] М. Ламперт, П. Марк. Инжекционные токи в твердых телах. Мир, М. (1973). 413 с.

[20] N.F. Mott, E.F. Davis. Electronic Processes in Non-Crystalline Materials. Clarendon Press, Oxford (1971). 438 p.

[21] С.С. Аплеснин, Магнитные и электрические свойства сильнокоррелированных магнитных полупроводников с четырехспиновым взаимодействием и с орбитальным упорядочением. Физматлит, М. (2013). 176 с.

Редактор Ю.Э. Китаев 